\title{
¿Avances en la lucha contra la discriminación salarial por razón de sexo?*
}

\author{
Progress in the fight against wage discrimination based \\ on sex?
}

\author{
Raquel Poquet Catalá ** \\ Profesora Derecho del Trabajo y de la Seguridad Social \\ Universidad de Valencia \\ ORCID ID: 0000-0001-9606-8832
}

Recibido: 9/3/2021

Aceptado: $26 / 3 / 2021$

doi: https://doi.org/10.20318/femeris.2021.6138

\begin{abstract}
Resumen. En este trabajo se realiza un análisis de la discriminación salarial por razón de sexo y de la normativa dictada al efecto de combatir dicha diferenciación y alcanzar la igualdad retributiva. Para ello, se realiza un estudio de la normativa existente, tanto a nivel internacional, como comunitario y nacional, así como de los diferentes tipos de discriminación existentes, esto es, directa e indirecta, con sus manifestaciones prácticas a través de la doctrina judicial. Adicionalmente, se analizan los factores más habituales que inciden en la creación de situaciones discriminatorias para la mujer trabajadora en materia salarial. Y, finalmente, se estudian las medidas establecidas recientemente por el legislador para hacer frente a dichas situaciones.

Palabras clave: discriminación salarial; igualdad retributiva; discriminación directa; discriminación indirecta; mujer trabajadora.
\end{abstract}

Abstract. In this work, it is carried out an analysis of wage discrimination based on sex and the regulations issued to combat such differentiation and achieve equal pay. For this, it is realized a study of the existing regulations, both at the international, community and national level, as well as the different types of existing discrimination, that is, direct and indirect, with its practical manifestations through judicial doctrine. Additionally, it is studied the most common factors that influence the creation of discriminatory situations for working women in terms of wages. And, finally, it is studied the measures recently established by the legislator to deal with these situations.

Keywords: Wage discrimination; equal pay; sex; direct discrimination; indirect discrimination; woman worker.

\footnotetext{
*Trabajo finalista del Premio 8M convocado por la Asociación Española de Derecho del Trabajo y la Seguridad Social. Evaluación del original efectuada por la Comisión de Igualdad de la AEDTSS.

${ }^{* *}$ Raquel.poquet@uv.es
} 


\section{Introducción}

La aprobación del RD 902/2020, de 13 de octubre, de igualdad retributiva entre mujeres y hombres, pone de manifiesto la necesidad de intervenir en un ámbito muy concreto parar continuar en el camino hacia la igualdad retributiva, concretamente, en el sistema de clasificación profesional, pues es constatada la existencia de una diferencia salarial entre personas trabajadoras varones y personas trabajadoras mujeres prestando un trabajo de igual valor. La práctica corrobora que la discriminación salarial por razón de sexo aún pervive, tanto directa como indirecta. Como dice la doctrina "la discriminación sufrida por las mujeres es la más antigua y persistente en el tiempo, la más extendida en el espacio (...) la que afecta al mayor número de personas y la más primaria, porque siempre se añade a las demás discriminaciones"1.

Esta brecha salarial es definida por la Comisión Europea ${ }^{2}$ como "la diferencia existente entre los salarios percibidos por los trabajadores de ambos sexos, calculada sobre la base de la diferencia media entre los ingresos brutos por hora de todos los trabajadores". Como indica la doctrina, la brecha salarial "refleja la segregación horizontal (que margina a muchas mujeres en actividades de escasa valoración social o en modalidades contractuales precarias) y vertical (en la promoción y en la carrera profesional). Es medidor de estereotipos (fundamentalmente vinculados al cuidado familiar), de infravaloraciones e hipervaloraciones así como de discriminaciones ocultas"3.

Así lo confirman los datos estadísticos cuando según datos del INE ${ }^{4}$ las mujeres tienen un salario medio anual de 20.051,58€, mientras los hombres llegan a 25.992,76€. Con ello, el salario medio anual femenino representa el 77,1\% del masculino. El 18,2\% de las mujeres tiene ingresos salariales menores o iguales que el Salario Mínimo Interprofesional (SMI), frente al 7,4\% de los hombres. Concretamente, dentro de los salarios más elevados, el 9,8\% de los hombres presenta unos salarios cinco veces o más superiores al SMI, frente al 5,0\% de las mujeres. Por su parte, las personas trabajadoras con ganancia baja (ganancia por hora por debajo de los $2 / 3$ de la ganancia media), representan el 16,7\% del total, de las cuales el 65,5\% son mujeres. En función del grupo profesional, se constata que la desigualdad en las remuneraciones no sólo es mayor en las categorías mejor remuneradas y puestos de mayor responsabilidad, sino que además aumenta en el extremo máximo de la distribución salarial. De esta forma, la discriminación por razón de sexo en los puestos directivos de la población está en torno al 40\% (el doble que la discriminación de género total). En el 1\% máximo (directores/as ejecutivos/as) representa más del 50\%, es decir, los hombres en puestos de dirección ejecutiva perciben el doble de salario que sus compañeras.

\footnotetext{
${ }^{1}$ Rey Martínez, F., El derecho fundamental a no ser discriminado por razón de sexo. Madrid. McGraw-Hill, 1995. p. 1.

${ }^{2}$ Comisión EuropeA, La brecha salarial entre hombres y mujeres en la Unión Europea, 2014. Disponible en https:// ec.europa.eu/info/policies/justice-and-fundamental-rights/gender-equality

${ }^{3}$ BALlester PASTOR, M.A., La discriminación retributiva por razón de sexo. Brecha salarial y desigualdades de género en el mercado de trabajo. Albacete: Bomarzo, 2018. p. 19.

${ }^{4}$ Ministerio de SANidAd, SERvicios Sociales E IguAldad. "Brecha salarial y científica de género", en Boletín Igualdad Empresa. Madrid: Ministerio de Sanidad, Servicios Sociales e Igualdad, 2018. Disponible en http://www.igualdadenlaempresa.es/novedades/boletin/docs/BIE_44_Brecha_salarial_y_cientifica_de_genero.pdf
} 
Además, según datos de la OIT $^{5}$, los países con los niveles más bajos de desigualdad salarial se encuentran en el grupo de países de ingreso alto, mientras que los niveles más elevados de desigualdad salarial se registran en el grupo de países de ingreso bajo y mediano. Entre los países de ingreso alto, la desigualdad salarial más baja la registra Suecia, y la más alta, Chile. Entre los países de ingreso bajo y mediano, Sudáfrica y Namibia cuentan con la desigualdad más alta, mientras que Armenia y Mongolia registran la desigualdad más baja.

Ello se observa también en el hecho de que, muchas veces, las mujeres perciben una retribución inferior a la de los hombres por trabajos del mismo valor, aun cuando los trabajos requieran los mismos requisitos en cuanto a habilidades, cualificación y experiencia, pues la infravaloración de las competencias y habilidades que se precisan para el desarrollo de determinados trabajos que tradicionalmente vienen desempeñando las mujeres lleva a que éstas estén situadas en los niveles más bajos de la clasificación profesional. En contraposición, se produce una sobrevaloración de los puestos de trabajo que ocupan los hombres y que se traducen en mejores salarios y mayores asignaciones de pluses y complementos, y esta sobrevaloración del trabajo masculino aparece también cuando los hombres se adentran en profesiones tradicionalmente desempeñadas por mujeres.

De cualquier forma, cabe precisar que la menor valoración del trabajo desempeñado por las mujeres se produce en la asignación de pluses y complementos salariales, pues éstos se aplican en mayor medida en puestos ocupados en su mayoría por hombres, en atención a la penosidad derivada del empleo de la fuerza física o a la toxicidad, circunstancias que no son tenidas en cuenta en puestos feminizados, cuando en éstos también se dan dichas situaciones.

La discriminación en la retribución es causa y efecto de la discriminación profesional de la mujer, produciéndose fenómenos como la segregación o feminización de los trabajos y la imposición de techos al ascenso profesional de las mujeres. Por ello, el principio de igualdad de retribución por razón de sexo constituye un elemento básico para la eliminación de las discriminaciones que pesan sobre el colectivo femenino ${ }^{6}$.

De ahí, la necesidad de aplicar el principio de transparencia retributiva, que según el art. 3 RD 902/2020, es definido como "aquel que, aplicado a los diferentes aspectos que determinan la retribución de las personas trabajadoras y sobre sus diferentes elementos, permite obtener información suficiente y significativa sobre el valor que se le atribuye a dicha retribución". Este principio de transparencia retributiva tiene por objeto la identificación de discriminaciones, tanto directas como indirectas, y, especialmente, las debidas a incorrectas valoraciones de puestos de trabajo, "lo que concurre cuando desempeñado un trabajo de igual valor de acuerdo con los artículos siguientes, se perciba una retribución inferior sin que dicha diferencia pueda justificarse objetivamente con una finalidad legítima y sin que los medios para alcanzar dicha finalidad sean adecuados y necesarios". Para

\footnotetext{
${ }^{5}$ BASE DE DATOS ESES, Informe mundial sobre salarios 2018/2019, OIT, 2019.

${ }^{6}$ RodríGuEz EsCANCIANO, S., "Sobre el valor del trabajo y la paridad salarial por razón de género ante una controvertida sentencia del Tribunal de Justicia de la Comunidad Europea (Comentario a la STJCE C-320/2000, de 17 de septiembre de 2002, asunto Lawrence)", RL, núm. 12, 2005 (versión on line)
} 
garantizar dicho principio se crea el registro retributivo y la auditoría salarial, aspectos que, con posterioridad, se analizarán.

\section{Marco normativo}

El primer antecedente se sitúa en el Convenio núm. 100 de la OIT sobre igualdad de remuneración ${ }^{7}$, cuyo art. 2 obliga a garantizar la aplicación a todas las personas trabajadoras del "principio de igualdad de remuneración entre la mano de obra masculina y la mano de obra femenina por un trabajo de igual valor". El acogimiento de este principio reviste una especial relevancia por cuanto la igualdad debe realizarse no sólo en los puestos de trabajo iguales, sino en los puestos de trabajo diferentes a los que se les reconoce igual valor, con lo que se trata de combatir con determinadas formas de discriminación indirecta. En el fondo, esta formulación amplia del principio parte del reconocimiento de que la amplitud de segregación entre los puestos masculinos y femeninos constituye el obstáculo más importante para una aplicación válida del principio de igualdad de remuneración ${ }^{8}$.

A nivel europeo, la erradicación de la discriminación salarial es un objetivo fundamental en la consecución del principio de igualdad entre mujeres y hombres. Así, el art. 119 del Tratado de Roma9 establece la igualdad de retribución entre trabajadoras y trabajadores que realizan el mismo trabajo, prohibiendo la discriminación salarial por razón de sexo. En el mismo sentido, el Protocolo 14 del Tratado de Maastricht recoge el principio de igualdad de trato salarial sin discriminación por razón de sexo y legitima la adopción de "medidas que prevean ventajas concretas destinadas a facilitar a las mujeres el ejercicio de actividades profesionales o a evitar o compensar algún impedimento en sus carreras profesionales", lo que vienen a ser las denominadas acciones positivas. Los arts. 2 y 3.3 del Tratado de la Unión Europea consagran el derecho a la igualdad entre hombres y mujeres como uno de los valores y tareas esenciales de la Unión, y los arts. 8 y 10 del Tratado de Funcionamiento de la Unión Europea establecen que, en todas sus acciones, la UE se fijará el objetivo de eliminar las desigualdades entre el hombre y la mujer y promover su igualdad, y luchar contra toda discriminación por razón de sexo. El art. 157 TFUE establece el principio de no discriminación retributiva entre hombres y mujeres, especificando que ello requiere igualdad retributiva por trabajo de igual valor. A su vez, el art. 157.2 TFUE precisa lo que se entiende por retribución a tales efectos. También, el art. 141 Tratado de Ámsterdam garantiza el "principio de igualdad de retribución entre trabajadoras y trabajadores para un mismo trabajo o para trabajos de igual valor".

Es con la Directiva 75/117/CEE ${ }^{10}$ cuando se incorpora formalmente el principio de igual retribución por trabajo de igual valor, ya que ésta define el concepto de igualdad retri-

\footnotetext{
${ }^{7}$ De 29 de junio de 1951, ratificado por España el 6 de noviembre de 1967.

${ }^{8}$ AA.VV., Evaluación de tareas. Ginebra: OIT, 1986. p. 152.

${ }^{9}$ De 25 de marzo de 1957. Literalmente, su apartado 1 establece que "cada Estado Miembro deberá asegurar que se aplica el principio de igual retribución para hombres y mujeres cuando éstos desempeñan trabajos iguales o de igual valor".

${ }^{10}$ De 10 de febrero, relativa al acercamiento de las legislaciones de los Estados miembros por lo que se refiere a la aplicación del principio de igualdad de remuneración entre trabajadores masculinos y femeninos.
} 
butiva como igual retribución para un trabajo igual o un trabajo al que se atribuye un mismo valor. La Directiva 2006/54/CE ${ }^{11}$ establece que para un mismo trabajo o para un trabajo al que se atribuye un mismo valor, se eliminará la discriminación directa e indirecta por razón de sexo en el conjunto de los elementos y condiciones de retribución, y particularmente, cuando se utilice un sistema de clasificación profesional para la determinación de las retribuciones, este sistema se basará en criterios comunes a las personas trabajadoras de ambos sexos, y se establecerá de forma que excluya las discriminaciones por razón de sexo.

Por su parte, la Carta de los Derechos Fundamentales de la Unión Europea ${ }^{12}$ establece en su art. 23 que "la igualdad entre mujeres y hombres deberá garantizarse en todos los ámbitos, inclusive en materia de empleo, trabajo y retribución. El principio de igualdad no impide el mantenimiento o la adopción de medidas que supongan ventajas concretas a favor del sexo menos representado".

El Código Práctico sobre la aplicación de la igualdad de retribución entre hombres y mujeres para un trabajo de igual valor ${ }^{13}$, ante las insuficiencias en la legislación salarial, se presenta como una medida concreta y útil encaminada a colmar dichas deficiencias, ayudando a gobiernos, empresas y representantes de personas trabajadoras a establecer unos sistemas retributivos que respeten mejor el principio de igualdad salarial. La Estrategia para la igualdad entre mujeres y hombres $2010-2015^{14}$ se basa en las prioridades de la Carta de la Mujer, siendo una de ellas la igualdad de salario por trabajo igual y trabajo de igual valor.

Y más, recientemente, el Parlamento Europeo ha adoptado varias resoluciones ${ }^{15}$ sobre la igualdad de retribución entre hombres y mujeres con recomendaciones sobre cómo aplicar mejor el principio de igualdad de retribución, con medidas de transparencia retributiva y sistemas de evaluación y clasificación de empleos no discriminatorios con respecto al sexo. En sus Conclusiones de 6 de diciembre de 2010 sobre el refuerzo del compromiso de eliminar las diferencias de retribución y la intensificación de las medidas a tal efecto, y sobre el examen de la aplicación de la Plataforma de Acción de Pekín ${ }^{16}$, el Consejo ha invitado a los Estados miembros a implantar medidas para hacer frente a las causas de las diferencias salariales entre hombres y mujeres, especialmente las que promuevan la transparencia salarial y unos sistemas de evaluación y clasificación de empleos no discriminatorios con respecto al empleo. Como fruto, la Recomendación 2014/124/UE ${ }^{17}$ facilita una serie de orientaciones dirigidas a los Estados miembros para ayudarlos a aplicar mejor y de forma más eficaz el principio de igualdad de retribución, con el fin de luchar contra las discriminaciones en materia de retribución y contribuir a hacer frente a la diferencia de retribución entre hombres y mujeres haciendo hincapié en la transparencia salarial. Dicha

\footnotetext{
${ }^{11}$ De 5 de julio, relativa a la aplicación del principio de igualdad de oportunidades e igualdad de trato entre hombres y mujeres en asuntos de empleo y ocupación.

${ }^{12}$ De 7 de diciembre de 2000, Niza.

${ }^{13}$ Resolución de 12 de junio de 1997.

${ }^{14}$ De 21 de septiembre de 2010.

${ }^{15}$ De 18 de noviembre de 2008, y de 24 de mayo de 2012.

${ }^{16}$ De 18 de diciembre de 2010.

${ }^{17}$ De 7 de marzo, de refuerzo del principio de igualdad de retribución entre hombres y mujeres a través de la transparencia.
} 
recomendación establece que los Estados debían optar por, al menos, una de las siguientes medidas: (i) derecho individual a la información retributiva de los niveles salariales desglosada por género (promedios) a requerimiento del trabajador y la trabajadora; (ii) atribución del derecho a esta información con carácter periódico, en beneficio de las personas trabajadoras y de sus representantes, en las empresas de al menos cincuenta personas trabajadoras; (iii) obligación de que las empresas de al menos doscientas cincuenta personas trabajadoras elaboren auditorías salariales (con promedios retributivos y análisis de sistemas de valoración de los puestos) que deben ponerse a disposición de los y las representantes; (iv) garantía de que la cuestión de la igualdad de retribución, en particular las auditorías salariales, se debata en el nivel adecuado de la negociación colectiva.

De cualquier forma, la doctrina judicial comunitaria ya dio a este derecho una perspectiva mucho más social conforme a la cual se tratase también de la mejora de las condiciones de vida y trabajo de los pueblos europeos, al fijar que "de este doble objetivo, económico y social, se desprende que el principio de igualdad de retribución forma parte de los fundamentos de la Comunidad"18. Así, admitió que si bien formalmente podría entenderse el art. 119 del Tratado como dirigido en exclusiva a los Estados, la prohibición de discriminación entre trabajadores y trabajadoras "se extiende asimismo a todos los convenios que tienen por objeto regular, de forma colectiva, el trabajo por cuenta ajena, así como a los contratos entre particulares"19.

Por otro lado, según se desprende de la doctrina judicial comunitaria, el TJUE ha aceptado la diferencia de retribución entre una mujer y un hombre que desempeñen un trabajo de igual valor cuando ésta está basada en los siguientes criterios: productividad (casos Danfoss y Royal Copenhagen), movilidad (casos Danfoss y Royal Copenhagen), formación (caso Danfoss), antigüedad (casos Danfoss y Nimz), trabajo a tiempo parcial (casos Kowalska, Boetel, Rinner-Kuhn, Bilka y Helming), acuerdos en convenios colectivos (casos Enderby y Kowalska), o fuerzas del mercado. El TJUE ${ }^{20}$ ha declarado que el criterio de flexibilidad de horarios y lugares de trabajo se puede aplicar en la valoración de puestos de trabajo si es importante para el cumplimiento de tareas específicas, pero no si el criterio se refiere a la calidad del trabajo que el trabajador o trabajadora desempeñe.

Asimismo, la Estrategia Europea para la Igualdad de Género 2020-2025 establece los objetivos estratégicos y las acciones clave de la Comisión Europea para este período 2020-2025 en materia de igualdad entre hombres y mujeres, entre las que se encuentra garantizar la igualdad de participación y de oportunidades en el mercado laboral, incluyendo la eliminación de la brecha retributiva de género.

A nivel nacional, destaca, en primer lugar, nuestra norma fundamental, en cuyo art. 9.2 encomienda a los poderes públicos promover las condiciones para que la libertad y la igualdad sean reales y efectivas, así como en su art. 14 consagra la igualdad y la prohibición de discriminación por razón de sexo. Descendiendo al ET, éste reconoce en el art. 4.2 c) como derecho básico de las personas trabajadoras el no ser discriminado directa o

\footnotetext{
${ }^{18}$ STJUE $43 / 75$, de 8 de abril de 1976, asunto Defrenne II

${ }^{19}$ STJUE 284/02, de 18 de noviembre de 2004, asunto Sass.

${ }^{20}$ SSTJUE 96/80, de 31 de marzo de 1981, asunto Jenkins; 184/89, de 7 de febrero de 1991, asunto Nimz.
} 
indirectamente para el empleo o una vez empleados, por razones de sexo. Asimismo, el art. 17.1 ET declara nulos y sin efecto los "preceptos reglamentarios, las cláusulas de los convenios colectivos, los pactos individuales y las decisiones unilaterales del empresario que den lugar en el empleo, así como en materia de retribuciones, jornada y demás condiciones de trabajo, a situaciones de discriminación directa o indirecta desfavorables por razón de edad o discapacidad o a situaciones de discriminación directa o indirecta por razón de sexo". El art. 28 obliga a la empresa "a pagar por la prestación de un trabajo de igual valor la misma retribución, satisfecha directa o indirectamente, y cualquiera que sea la naturaleza de la misma, salarial o extrasalarial, sin que pueda producirse discriminación alguna por razón de sexo en ninguno de los elementos o condiciones de aquella", y el art. 22.3 establece que "la definición de los grupos profesionales se ajustará a criterios y sistemas que, basados en un análisis correlacional entre sesgos de género, puestos de trabajo, criterios de encuadramiento y retribuciones, tengan como objeto garantizar la ausencia de discriminación, tanto directa como indirecta, entre mujeres y hombres. Estos criterios y sistemas, en todo caso, cumplirán con lo previsto en el artículo 28.1".

De hecho, fue la LO $3 / 2007^{21}$ la que reguló de forma expresa la igualdad en todos los ámbitos, y especialmente en el laboral, entre mujeres y hombres, garantizando la igualdad y la prohibición de discriminación tanto directa como indirecta por razón de sexo $^{22}$ y regulando las acciones positivas con el fin de adoptar medidas específicas a favor de las mujeres para corregir situaciones de desigualdad con respecto de los hombres. Como novedad incorporó los planes de igualdad que han de elaborar las empresas como compromiso de las mismas con la igualdad de oportunidades entre mujeres y hombres a través de la aplicación de medidas de igualdad que lleven a la eliminación de posibles desigualdades.

Posteriormente, el RDL 6/2019, de 1 de marzo, de medidas urgentes para garantía de la igualdad de trato y de oportunidades entre mujeres y hombres en el empleo y la ocupación, configura un sistema que mejora lo establecido en la Recomendación de la Comisión de 7 de marzo de 2014, y que combina varias de las opciones establecidas en dicho texto, pues el sistema español de registro retributivo permite el acceso de la representación legal de las personas trabajadoras a la información retributiva desglosada y promediada en todas las empresas, y no solo en aquellas con al menos cincuenta personas trabajadoras como establece la recomendación. Asimismo, la auditoría salarial, que en la recomendación se refiere a las empresas de al menos doscientas cincuenta personas trabajadoras, en la norma española se aplica a todas las empresas que tienen la obligación de tener planes de igualdad que, una vez transcurridos los plazos transitorios establecidos en el RDL 6/2019 alcanzará en España a todas las empresas de al menos cincuenta personas trabajadoras.

\footnotetext{
${ }^{21}$ De 22 de marzo, para la igualdad efectiva de mujeres y hombres.

${ }^{22} \mathrm{El}$ art. 6 define la discriminación directa e indirecta. Así "se considera discriminación directa por razón de sexo la situación en que se encuentra una persona que sea, haya sido o pudiera ser tratada, en atención a su sexo, de manera menos favorable que otra en situación comparable. Se considera discriminación indirecta por razón de sexo la situación en que una disposición, criterio o práctica aparentemente neutros pone a personas de un sexo en desventaja particular con respecto a personas del otro, salvo que dicha disposición, criterio o práctica puedan justificarse objetivamente en atención a una finalidad legítima y que los medios para alcanzar dicha finalidad sean necesarios y adecuados".
} 


\section{Tipos de discriminación}

\subsection{Discriminación directa}

El art. 6 LOIEMH define los dos tipos de discriminación existentes, esto es, directa e indirecta. Su apartado 1 -en consonancia con el art. 2.1 a) c ${ }^{23}$ - define la discriminación directa por razón de sexo como "la situación en que se encuentra una persona que sea, haya sido o pudiera ser tratada, en atención a su sexo, de manera menos favorable que otra en situación comparable". Se trata, como indica la doctrina ${ }^{24}$ del "primer peldaño de la prohibición de discriminación, absolutamente básico y fundamental y, por tanto, inderogable", esto es, el "núcleo fundamental de la interdicción de la discriminación por razón de sexo"25.

De dicha definición, la doctrina ${ }^{26}$ extrae los siguientes elementos. Por un lado, se constituye como un concepto bilateral en torno a la discriminación directa, pues señala cuando "una persona", sea una mujer o un hombre. En segundo lugar, se requiere un tratamiento desfavorable al indicar "sea, haya sido o pudiera ser tratada, de manera menos favorable". En tercer lugar, se requiere un elemento comparativo cuando remarca "que otra en situación comparable". Y, por último, debe exigir un elemento causal, esto es, "en atención a su sexo".

No obstante, este concepto jurídico aséptico basado en el sexo sin añadidos socioculturales ${ }^{27}$ genera un obstáculo que ha dado lugar a muchos conflictos y problemas en versión judicial, principalmente en materia retributiva, pues el principio de igual retribución por igual trabajo permitió, en aquellos momentos, erradicar las dobles escalas salariales asignando a la misma categoría profesional dos retribuciones distintas según el sexo, siendo la de las mujeres considerablemente inferior a la de los hombres. Su denuncia era imposible cuando no había posibilidad de comparación al estar mujeres y hombres en distintas categorías profesionales.

De ahí, la necesidad de establecer un principio de igual retribución por "trabajo de igual valor" permitiendo de esta forma comparar trabajos de dos categorías profesionales que se encuentran ocupadas, por imposición, exclusivamente una por hombres y otra por mujeres -discriminación directa-, o que se encuentran, por motivos socioculturales, ocupadas mayoritariamente una por hombres y otra por mujeres -discriminación indirecta-, con la consiguiente ampliación de los ámbitos de la comparación aunque los trabajos sean distintos , dando lugar a la "concepción flexible del término de comparación"28.

${ }^{23}$ De 5 de julio de 2006, relativa a la aplicación del principio de igualdad de oportunidades e igualdad de trato entre hombres y mujeres en asuntos de empleo y ocupación (refundición).

${ }^{24}$ REY MARTínez, F., El derecho fundamental a... op. cit.

${ }^{25}$ Serra Cristóbal, R., "La discriminación indirecta por razón de sexo", en RidAura Martínez, J.; AzNAR Gómez, M., (Coords.) Discriminación versus diferenciación (Especial referencia a la problemática de la mujer). Valencia: Tirant lo Blanch, 2004. p. 365.

${ }^{26}$ SÁEz LARA, C., Mujeres y mercado de trabajo. Madrid: CES, 1994. p. 56.

${ }^{27}$ Lousada Arochena, J.F., El derecho fundamental a la igualdad efectiva de mujeres y hombres. Fundamentos del derecho a la igualdad de género y, en especial, su aplicación en el Derecho del Trabajo y de la Seguridad Social. Valencia: Tirant lo Blanch, 2014 (versión on line)

${ }^{28}$ Quintanilla Navarro, B., Discriminación retributiva. Diferencias salariales por razón de sexo. Madrid: Marcial Pons, 1996. 
Un claro ejemplo de este tipo de discriminación retributiva directa se halla en la STJUE Caso McCarthys $\mathrm{Ltd} .^{29}$ cuando una trabajadora recibía una retribución inferior a la percibida por el varón que ocupaba con anterioridad el mismo puesto; o cuando se abona la cotización a un régimen profesional de pensiones a través de un complemento del salario que se reconoce a los varones siempre y a las mujeres sólo desde los 25 años ${ }^{30}$; cuando los subsidios familiares se pagan a todos los varones y solo a las mujeres cuyo esposo sea incapaz o gane menos del salario mínimo ${ }^{31}$; cuando el salario bruto se reduce a las funcionarias casadas con otros funcionarios en cuanto el salario conjunto de ambos supere determinado techo ${ }^{32}$; cuando las trabajadoras, en trabajos de producción con un valor superior, cobran menos que un varón almacenero ${ }^{33}$; o cuando las mujeres nunca están en situación de devengar una indemnización complementaria por despido ${ }^{34}$.

En este sentido, la doctrina judicial comunitaria ${ }^{35}$ recuerda que "la igualdad de retribución debe garantizarse no solo en función de una apreciación global de las gratificaciones concedidas a los trabajadores, sino también a la vista de cada elemento de la retribución considerado aisladamente". Y a efectos de la comparación, señala que debe estarse a "la naturaleza del trabajo efectivamente realizado", sin que la integración en la misma categoría profesional suponga igualdad de trabajos o de su valor.

En España, un claro ejemplo de discriminación salarial directa se halla en el caso Avón, donde la discriminación se basa en la segregación de sexos en dos categorías con salarios diferentes. El TC ${ }^{36}$ anuló la STCT que consideró un reclamo de trabajo de igual valor como conflicto de intereses no judicializable.

En la jurisdicción ordinaria, los ejemplos más claros de discriminación salarial directa se encuentran en casos donde se declara discriminatorio un plus de convenio derivado de un anterior plus de asistencia ${ }^{37}$, un plus de asiduidad ${ }^{38}$, con cuantías diferentes para hombres y mujeres, o en la misma estructura del salario, donde el de los hombres era un salario base superior al de las mujeres, y aunque éstas cobraban la diferencia a través de un plus de compensación, el diferente tratamiento a efectos de absorción y compensación entre el salario base y los pluses salariales determinaba la existencia de la desigualdad ${ }^{39}$. Así también sucede con una retribución extrasalarial consistente en un subsidio familiar con diferentes requisitos de acceso para los varones trabajadores, donde se requería estar casados, con o sin hijos, y convivir con su esposa, o ser viudos o separados legalmente con hijos a cargo, y otros diferentes aplicables a las mujeres trabajadoras, para las cuales se requería ser viudas o separadas legalmente con hijos a cargo ${ }^{40}$.

\footnotetext{
${ }^{29}$ De 27 de marzo de 1980, C-129/1979.

${ }^{30}$ STJUE de 11 de marzo de 1981, C-69/1980, asunto Worringham.

${ }^{31}$ STJUE de 9 de junio de 1982, C-58/1981, Comisión contra Luxemburgo.

${ }^{32}$ STJUE de 18 de septiembre de 1984, C-23/1983, asunto Liefting.

${ }^{33}$ STJUE de 4 de febrero de 1988, C-157/1986, asunto Murphy.

${ }^{34}$ STJUE de 17 de febrero de 1993, C-173/1991, asunto Comisión contra Bélgica.

${ }^{35}$ STJUE de 26 de junio de 2001, C-381/1999, asunto Brunnhofer.

${ }^{36}$ STC 145/1992, de 13 de octubre.

${ }^{37}$ STCT de 17 de junio de 1986.

${ }^{38}$ STCT de 22 de julio de 1986.

${ }^{39}$ STCT de 17 de julio de 1986.

${ }^{40}$ STS de 1 de diciembre de 1987.
} 
Posteriormente, la doctrina judicial ha hallado un supuesto de doble escala salarial en la medida en que "la empresa demandada retribuye el trabajo de los hombres como peón collidor a razón de 724 pesetas/hora, y el de las mujeres que prestan idénticos servicios a razón de 602 pesetas/hora" 41 , así como un supuesto donde se niega el plus de calidad a una camarera, plus que venía siendo abonado a sus compañeros varones, alegando la empresa que esa situación provenía de una concesión anterior ${ }^{42}$. Asimismo, se ha estimado discriminatorio aplicar a la trabajadora la absorción de un complemento salarial cuya absorción no se aplicaba a sus compañeros masculinos ${ }^{43}$, o cuando un complemento personal que, atendiendo al promedio abonado a las trabajadoras, era inferior al promedio abonado a los trabajadores, sin que la empleadora hubiera justificado la expuesta diferencia en criterios objetivos ${ }^{44}$.

Asimismo, la doctrina judicial ${ }^{45}$ se ha pronunciado en un caso donde una mujer trabajadora había percibido durante diversos años unas retribuciones sustancialmente inferiores a la de los otros cuatro responsables de departamento, todos ellos varones, cuando todos ellos y ella ocupaban el mismo puesto, con idéntica categoría. Ante esta situación la empresa no pudo aportar una justificación objetiva y razonable, alegando únicamente, que los diferentes departamentos tienen cometidos y responsabilidades diferentes, justificación que el órgano judicial calificó de sinsentido.

\subsection{Discriminación indirecta}

La discriminación indirecta, tal y como indica el art. 6.2 LOIEMH -en consonancia con el art. 2.1b) Directiva 2006/54/CE-, es aquella "situación en que una disposición, criterio o práctica aparentemente neutros pone a personas de un sexo en desventaja particular con respecto a personas del otro, salvo que dicha disposición, criterio o práctica puedan justificarse objetivamente en atención a una finalidad legítima y que los medios para alcanzar dicha finalidad sean necesarios y adecuados".

Según el TC, la discriminación directa es "aquel tratamiento diferenciado perjudicial en razón del sexo donde el sexo sea objeto de consideración directa", mientras que la indirecta comprende "aquellos tratamientos formalmente no discriminatorios de los que derivan, por las consecuencias fácticas que tienen lugar entre trabajadores de distinto sexo, consecuencias desiguales perjudiciales por el impacto diferenciado y desfavorable que tratamientos formalmente iguales o tratamientos razonablemente desiguales tienen sobre los trabajadores de uno u otro sexo a causa de la diferencia de sexo" ${ }^{46}$.

Los elementos configuradores de este tipo de discriminación son, por un lado, la existencia de una medida aparentemente neutra adoptada por una empresa. En segundo lugar, el impacto adverso que tiene dicha medida sobre un colectivo determinado. En

\footnotetext{
${ }^{41}$ STSJ Comunidad Valenciana, de 28 de septiembre de 1999, rec. núm. 2354/1999.

${ }^{42}$ STSJ Canarias, de 21 de diciembre de 2006, rec. núm. 485/2003.

${ }^{43}$ STSJ Madrid, de 26 de febrero de 2007, rec. núm. 170/2007.

${ }^{44}$ STS de 22 de abril de 2014, rec. núm. 2191/2013.

${ }^{45}$ STSJ Andalucía, de 14 de febrero de 2018, rec. núm. 2089/2017.

${ }^{46}$ STC 145/1991, de 1 de julio.
} 
tercer lugar, la categorización de ese colectivo dentro de los colectivos protegidos por la prohibición de discriminación. Y por último, la ausencia de una justificación de la medida ajena a la causa de discriminación de que se trate ${ }^{47}$.

El primer elemento hace referencia a aquellos tratamientos formalmente no discriminatorios, pero de los que se derivan, por las diferencias fácticas que tienen lugar entre las personas de distinto sexo, consecuencias desiguales perjudiciales para uno de dichos colectivos. En este sentido, se estima el criterio del esfuerzo o fuerza física como elemento "sospechoso (...) como único criterio de valoración, por lo que tiene de cualidad predominantemente masculina, que determina, en principio, que no se trate de un criterio de valoración sexualmente neutral, sino que implica una ventaja injustificada para los varones, admitiendo no obstante, aunque con un carácter muy restrictivo, su posible operabilidad" 48 .

El segundo elemento, referido al impacto adverso se traduce en una categorización de los trabajos femeninos como trabajos de "menor valor" que los masculinizados, utilizando para establecer las diferentes categorías profesionales criterios en sí mismos discriminatorios. Los perjuicios también pueden ser de carácter económico, consistiendo en la menor retribución económica para las profesiones realizadas generalmente por las mujeres y una más elevada para los puestos ocupados tradicionalmente por los hombres, o puede tratarse de la asignación de un complemento o ayuda económica aparejados exclusivamente a ciertos puestos de trabajo desempeñados casi totalmente por hombres ${ }^{49}$.

En cuanto al tercer elemento referido a la justificación, se ha analizado el criterio de la "fuerza" o "fatiga muscular", entendiendo que una remuneración proporcional al grado de esfuerzo físico de la función a desempeñar, pese a que genera en la práctica una nivel salarial más elevado para hombres que para mujeres no puede entenderse contrario a la Directiva 75/117, sobre el principio de igualdad en las remuneraciones salariales entre las personas trabajadoras masculinas y femeninas, si el desempeño del trabajo exige objetivamente un empleo mayor de la fuerza física. De esta misma forma, el $\mathrm{TC}^{50}$ ha admitido que el criterio del esfuerzo físico puede ser tenido en cuenta en el acceso al empleo, pero supeditado a la doble condición de que dicho factor sea un elemento esencial en la tarea de que se trate y de que en la valoración de ésta no se tenga en cuenta el esfuerzo físico como criterio único de valoración, sino que se combine con otras características más neutras en cuanto a impacto en cada uno de los sexos.

La doctrina judicial comunitaria ha tenido ocasión de pronunciarse en diversos casos. Por un lado, en un contexto de no transparencia del sistema de retribución de la empresa, admite realizar una comparativa global "a partir de un número relativamente importante de personas trabajadoras por cuenta ajena”, de la cual deduce una retribución media de las trabajadoras mujeres de cuantía inferior a la retribución media de los trabajadores varones $^{51}$. En otro caso, la comparativa lo es entre categorías de logopedas, en su mayoría mu-

\footnotetext{
${ }^{47}$ LousAdA ARochenA, J.F., El derecho fundamental a... op. cit.

${ }^{48}$ STC 250/2000, de 30 de octubre.

${ }^{49}$ SERRA CRISTóbal, R., "La discriminación indirecta por... op. cit.

${ }^{50}$ STC 250/2000, de 30 de octubre.

${ }^{51}$ STJUE de 17 de octubre de 1989, C-109/1988, Asunto Danfoss.
} 
jeres, y categoría de farmacéuticos, en su mayoría hombres, sujetos a distintos convenios colectivos. El TJUE considera que "no basta, para justificar objetivamente la diferencia de retribución entre dos funciones del mismo valor (...) alegar el hecho de que las respectivas retribuciones de estas dos funciones se determinaron mediante procesos de negociación colectiva diferentes pese a participar en ellos las mismas partes, y cada una de los cuales, considerado por separado, no tienen en sí mismo efecto discriminatorio" ${ }^{52}$.

En otro caso, el TJUE va más allá del ámbito estrictamente empresarial, y considera que la comparación puede tener un carácter supraempresarial, en la medida en que estima que "el principio de igualdad de retribución entre trabajadores y trabajadoras es aplicable también cuando la retribución se fija a través de negociaciones colectivas o de negociaciones de ámbito local", aunque matizó que "no obstante, el órgano jurisdiccional nacional puede tomar en consideración dicha circunstancia a la hora de apreciar si las diferencias entre las retribuciones medias de dos grupos de trabajadores se deben a factores objetivos y ajenos a cualquier discriminación por razón de sexo"53. No obstante, esta comparación no se ha admitido en empresas implicadas en procesos de externalización, señalando que las desigualdades de retribución prohibidas en el art. 157 TFUE "son imputables a una única causa", pues, en caso contrario, "falta una entidad que sea responsable de la desigualdad y que pudiera restablecer la igualdad de trato"54.

En el ámbito nacional y en materia retributiva, se encuentra el ejemplo tipo en el caso del Hospital Gregorio Marañón, situación donde existía una diferencia retributiva establecida en convenio colectivo entre la categoría profesional de peón, ocupado mayoritariamente por hombres, y la categoría profesional de limpiadores, ocupada mayoritariamente por mujeres, cuando ambas categorías profesionales realizaban trabajos manuales considerados de igual valor. El TC ${ }^{55}$ afirma que "la noción de discriminación indirecta (...) incluye los tratamientos formalmente no discriminatorios de los que derivan, por las diferencias fácticas que tienen lugar entre trabajadores de diverso sexo, consecuencias desiguales perjudiciales por el impacto diferenciado y desfavorable que tratamientos formalmente iguales o tratamientos razonablemente desiguales tienen sobre los trabajadores de uno y otro sexo a causa de la diferencia de sexo".

El TC se refiere en dicho caso al esfuerzo físico como factor de diferenciación considerándolo receptor de "valores correspondientes a los rasgos medios de trabajadores de un solo sexo para determinar en qué medida un trabajo exige esfuerzo u ocasiona una fatiga o es físicamente penoso", produciendo en el caso discriminación, porque se "corresponde única y exclusivamente con un estándar del trabajador varón". Además, se refiere a la sumisión de los convenios colectivos a las exigencias de la jerarquía normativa "de modo que han de ceder, necesariamente, ante el derecho fundamental consagrado en el artículo 14 de la Constitución" ${ }^{\prime 56}$.

\footnotetext{
${ }^{52}$ STJUE de 27 de octubre de 1993, C-127/1992, Asunto Enderby.

${ }^{53}$ STJUE de 31 de mayo de 1995, C-400/1993, Asunto Royal Copenhagen.

${ }^{54}$ SSTJUE de 17 de diciembre de 2001, C-320/2000, Asunto Lawrence; de 13 de enero de 2004, C-256/2001, Asunto Allonby.

${ }^{55}$ STC $145 / 1991$, de 1 de julio.

${ }^{56}$ STC 145/1991, de 1 de julio.
} 
En sentido similar, el caso Antonio Puig ${ }^{57}$ analiza, pero con mayor detenimiento, el criterio del esfuerzo físico como criterio de diferenciación retributiva, admitiéndolo solo "si se acreditase de forma indubitada que el esfuerzo físico constituye un elemento determinante absoluto de aptitud para el desarrollo de la tarea, o bien, que se trate de un elemento esencial en esta, siendo preciso, aún en estos casos, que se combinen con otros rasgos tipificadores neutros desde el punto de vista que interesa considerar", circunstancias excepcionales que no se daban en el caso. El TC considera que el esfuerzo físico como criterio de diferenciación es un criterio sexista, de modo que la prohibición de discriminación por sexo en materia salarial también se ignora cuando se produce una hipervaloración de trabajos en los que sólo han sido tomados en consideración a efectos salariales rasgos inherentes a uno de los sexos, en detrimento del otro.

Posteriormente, analiza el caso Galletas Fontaneda ${ }^{58}$, supuesto criticado, donde el departamento de producción, ocupado por hombres, percibía una retribución superior al departamento de empaquetado, ocupado por mujeres, diferencia justificada por la mayor responsabilidad y concentración de las tareas de producción. El TC solo consideró discriminatoria esa inferior retribución de las mujeres empaquetadoras destinadas al departamento de producción, supuesto propio de una discriminación salarial directa. Como indica la doctrina ${ }^{59}$, con este caso, el TC da un paso atrás en la línea jurisprudencial establecida por el caso Gregorio Marañón, ya que no aprecia la discriminación indirecta de la clasificación de funciones dentro de la empresa en atención al sexo, pese a que el departamento de producción, integrado casi en su totalidad por hombres, recibe un salario base diario superior al departamento de envasado, preferentemente integrado por mujeres.

En el caso Gomaytex ${ }^{60}$ vuelve a su anterior línea, y el TC analiza los criterios de esfuerzo y penosidad. No obstante, en el caso del Convenio colectivo de manipulación y envasado de agrios de Murcia ${ }^{61}$ considera un "intenso" esfuerzo físico con "riesgo dorsolumbar" como justificativo de las diferencias retributivas apreciables en las tareas masculinizadas $^{62}$. Señala el TC que "no cabe partir de que el esfuerzo físico sea un criterio de valoración absolutamente rechazable sin fisuras", ya que puede encontrar oportunidad su aplicación cuando las concretas circunstancias de un determinado caso así lo requieran, y este es el caso en que, por primera vez, justifica el recurso al esfuerzo físico como criterio de clasificación, pues queda claramente justificado el esfuerzo físico intenso y sus posibles riesgos en "razón del permanente manejo por quien realice funciones de carga y descarga de camiones y apilado de cargas de 20 kilos de peso, por el riesgo dorsolumbar que la constante exigencia física que esa actividad entraña".

Por su parte, la doctrina judicial, superado el estadio de admitir únicamente la distribución retributiva directa, considera también discriminaciones indirectas cuando se

\footnotetext{
${ }^{57}$ STC 58/1994, de 28 de febrero.

${ }^{58}$ STC 286/1994, de 27 de octubre.

${ }^{59}$ Rey MARTínEz, F., El derecho fundamental a... op. cit.

${ }^{60}$ STC 147/1995, de 16 de octubre.

${ }^{61}$ STC 250/2000, de 30 de octubre.

${ }^{62}$ Rodríguez-Piñero y Bravo-Ferrer, M., "Feminización de tareas y masculinización de valoraciones”, RL, núm. 3, 2001. p. 1 .
} 
aprecia un trabajo igual o de igual valor y la diferencia no presente justificación suficiente, no valiendo al efecto la diferencia de funciones ${ }^{63}$, criterios subjetivos $^{64}$, el esfuerzo físico ${ }^{65}$, la individualización de las cuantías ${ }^{66}$, la diferencia de categorías ${ }^{67}$, el manejo de vehícu$\operatorname{los}^{68}$, u otras tareas prohibidas a mujeres ${ }^{69}$, la exclusión del convenio colectivo ${ }^{70}$, o la actitud general de la empresa en su compromiso con la igualdad sexual ${ }^{71}$.

También se han encontrado pronunciamientos más recientes, donde se ha considerado discriminación salarial la práctica empresarial de no abonar el plus voluntario variable y absorbible a las trabajadoras con nivel salarial IV, facturistas y camareras de piso, y sí a los trabajadores en el mismo nivel aparentemente neutra relacionadas con determinadas categorías de personas trabajadoras, ostentadas por mujeres, que las sitúa en una posición de desventaja con otras categorías del mismo nivel retributivo, ocupadas

${ }^{63}$ STSJ Madrid, de 15 de octubre de 1991, donde se considera discriminatorio el tratamiento retributivo diferente en orden a las gratificaciones extraordinarias cuando trabajadores hombres y trabajadoras mujeres "realizan unas funciones que representan trabajos de igual valor como corresponde a la misma categoría que tienen, y al mismo nivel retributivo en cuanto a salario base y plus convenio".

${ }^{64}$ STS Cataluña, de 14 de septiembre de 1992, donde "la demandante tiene la misma categoría profesional que sus compañeros varones, desempeña funciones similares e incluso uno de ellos es subordinado suyo, pero percibe una remuneración muy inferior (...) (por un) llamado complemento de mejora de empresa (que) contempla conceptos tan incorrectos como solución de problemas, iniciativa, colaboración, innovación y dedicación no medidos con arreglo a unos criterios objetivos o de rendimiento, sino puramente subjetivos de la dirección de la empresa y que por extraña coincidencia siempre son inferiores en el caso de la demandante".

${ }^{65}$ STSJ Cataluña, de 13 de julio de 1993, donde las diferencias obedecen a "un concepto retributivo, el plus de conocimientos especiales, que es percibido en sus niveles más altos por los varones, mientras que el colectivo de mujeres (que junto con aquellos comparten la común categoría de especialistas) se les adjudica los niveles inferiores del baremo retributivo de dicho complemento", cuando es que "no responde tanto a unos conocimientos especiales que la empresa no valora (sino con un carácter meramente residual, no significativo), cuanto al esfuerzo físico como variante fundamental".

${ }^{66}$ STSJ País Vasco, de 10 de octubre de 1995, rec. núm. 1417/1995, que señala que aunque el complemento salarial "varía de una persona a otra, incluso aunque efectúen el mismo trabajo y tengan idéntica categoría, concurre la circunstancia de que su importe en el caso de cualquiera de los varones, es superior al más alto de los asignados a las mujeres, pese a que estas realicen un trabajo de igual valor".

${ }^{67}$ STSJ Andalucía, de 29 de diciembre de 1995, rec. núm. 1307/1995, en un caso donde el "menor salario percibido por las trabajadoras actoras frente a los trabajadores que realizan un trabajo equivalente o de igual valor (se deriva de su clasificación) no como limpiadoras sino como mozos, sin que medie una justificación objetiva y razonable de la desigualdad salarial". En sentido similar, SSTSJ País Vasco, de 1 de julio de 1999; Madrid, de 30 de octubre de 2009, rec. núm. 4259/2009, donde una trabajadora realiza las mismas funciones que un compañero trabajador, tienen las mismas responsabilidades, y la empresa se basa simplemente en el hecho de que tienen diferentes categorías para dar un tratamiento salarial diferente.

${ }^{68}$ STSJ Navarra, de 9 de junio de 1997, donde se considera discriminación retributiva cuando las trabajadoras ostentan "la categoría de especialistas, cometido que es realizado en el almacén y cuyas funciones consisten en el empaquetamiento de pedidos, confección de éstos, proveyéndose para ello de las piezas colocadas en las distintas estanterías, así como barrido de la fábrica (mientras) los trabajadores masculinos que ostentan la misma categoría que las trabajadoras y que también realizan sus servicios en el almacén, realizan el manejo de las carretillas y elevadoras, sin que las trabajadoras tengan acceso al manejo de maquinaria por decisión empresarial".

${ }^{69}$ STSJ Canarias, de 29 de octubre de 1999, donde "la equiparación salarial (....) se rompe a través de una decisión unilateral del empresario que atribuye en exclusiva a los hombres ciertas tareas que pueden realizar las mujeres, y que determinan una diferencia de retribución; e incluso reconoce un complemento de calidad a parte del colectivo de hombres sin que exista una justificación fáctica suficiente para ello".

${ }^{70}$ STSJ Castilla-La Mancha, de 29 de junio de 2000, rec. núm. 544/1999, donde "reclaman las actoras, pues son todas ellas mujeres, las diferencias de retribución entre las que venían percibiendo, y las que corresponderían a la categoría de trabajos idénticos, conforme al convenio colectivo del ayuntamiento demandado, tal y como por ejemplo, la categoría de operarios de limpieza", justificando las diferencias el ayuntamiento en las peculiaridades de la contratación.

${ }^{71}$ STS Cataluña, de 23 de noviembre de 2000, rec. núm. 5683/2000, donde se constata que "las trabajadoras de categoría de oficial primera no perciben la misma cantidad en concepto de plus de empresa que los hombres de su misma categoría". 
preferentemente por hombres ${ }^{72}$. Así también la creación en el convenio colectivo de una nueva categoría profesional, la de peón b), que es ocupada mayoritariamente por mujeres y cuyas funciones son comparables y de igual valor a las de especialista, este último mejor retribuidas "no siendo suficiente la afirmación de que la noma se pactó a los efectos de persecución de unos fines lícitos en principio neutros y ajenos a la discriminación como viabilidad empresarial, conservación y creación de empleo...sin que en el caso de autos ningún elemento permita concluir que esa creación de categoría peón b) (...) constituya una medida efectivamente necesaria ni justificada por razones objetivas diferentes a una situación de discriminación, sino que tan solo responde al hecho cierto y real de que para un mismo puesto se retribuye en cuantía inferior a las mujeres"73. Asimismo, también se ha enjuiciado la autonomía o responsabilidad, concretamente "un plus voluntario, no vinculado expresamente a circunstancia laboral o prestacional alguna (...) con unas cantidades significadamente inferiores en los departamentos integrados exclusivamente por mujeres $(10,37 € /$ mes por persona en el de pisos) respecto a las que otorga en los departamentos mayoritariamente ocupados por hombres $(118,42$ y 168,19€/mes en cocina y bares, respectivamente)", apreciando una clara discriminación indirecta pues "la autonomía o la responsabilidad (...) carecen aquí de significación al respecto porque el segundo (la responsabilidad), sin mayores precisiones, es decir, en lo que puede entenderse como la necesidad de cumplir con las obligaciones concretas de su puesto de trabajo, de conformidad a las reglas de la buena fe y diligencia como uno de los deberes básicos de los trabajadores (artículo 5 del ET), es obviamente predicable y exigible en cualquier prestación laboral; y el primero (la autonomía), tratándose en todos los casos de servicios por cuenta ajena, y a salvo de cualquier otra circunstancia o explicación más razonable, no parece que puedan servir para justificar la importante diferencia retributiva detectada por la autoridad laboral"74.

\section{Variables de la brecha salarial}

La brecha salarial entre hombres y mujeres ya no se halla, en la actualidad, generalmente, en la diferente retribución por un trabajo igual, sino que, ahora, la diferencia retributiva es mucho más compleja al desaparecer las manifestaciones externas de la discriminación, aun a pesar de pervivir los estereotipos sexistas sobre el valor del trabajo femenino. Por ello, la necesidad de actuar desde diferentes planos. Básicamente, se pueden agrupar en tres los factores que suponen una desigualdad salarial, cuales son, la segregación ocupacional, horizontal y vertical; los criterios de atribución de valor a cada tipo de trabajo, esto es, ordenación de ocupaciones, tareas y especialidades; división sexual del trabajo y falta de corresponsabilidad en el ámbito familiar.

${ }^{72}$ STSJ Canarias, de 30 de junio de 2008, rec. núm. 834/2007. Así también la STSJ País Vasco, de 30 de abril de 2019, rec. núm. 638/2019.

${ }^{73}$ STSJ Galicia, de 29 de mayo de 2014, rec. núm. 523/2014.

${ }^{74}$ STS de 14 de mayo de 2014, rec. núm. 2328/2013. 


\subsection{Segregación ocupacional}

La segregación ocupacional hace referencia a la tendencia de que existe una mayor presencia de personas trabajadoras varones en unos sectores o ramas de actividad, profesiones o puestos, mientras que en otros sectores o puestos predominan las personas trabajadoras mujeres. En definitiva, y como es de sobra conocido, existen sectores feminizados y otros masculinizados. En general, las mujeres suelen estar más presentes en el sector servicios, sanidad o educación, mientras que en el sector industrial o técnico especializado predominan los hombres ${ }^{75}$. En pocas palabras, la segregación horizontal, la cual se alimenta, en cierta forma, de la percepción de las mujeres de que en determinadas profesiones masculinizadas sufrirán mayor discriminación, tendrán menos posibilidades profesionales o se podrán encontrar con un clima de trabajo hostil ${ }^{76}$. De ahí, la necesidad de actuar mediante políticas educativas, coeducativas y de promoción contra la segregación horizontal, además de políticas laborales antidiscriminatorias.

Por su parte, la segregación vertical es la que resulta de la mayor presencia masculina en puestos de más alto nivel y más exigentes formativa y profesionalmente, o que impliquen mando, jefatura o responsabilidad. Es lo que se denomina también "techo de cristal"77, que expresa las dificultades a las que se hallan las mujeres para poder promocionar y seguir en la carrera profesional.

De hecho, si se analizan los datos estadísticos sobre las áreas de estudio, se puede observar como el porcentaje de mujeres en sectores relacionados con la sanidad, atención, cuidado o educación es mayor en relación con los hombres, sectores que tienen peor inserción laboral, más paro, peores contratos y salarios más bajos ${ }^{78}$. Al igual que corroboran los estudios sobre las grandes cifras a nivel mundial, ni el éxito académico ni la mejor preparación o nivel formativo de las mujeres son garantía de acceso al mercado en condiciones de igualdad. Sin embargo, según el INE la proporción de mujeres que tienen empleo en relación con la población en edad de trabajar es menor a la de los hombres $(43,10 \%$ frente a $54,60 \%)$, siendo mayor la proporción de mujeres con formas atípicas, irregulares o informales de empleo o más vulnerables ${ }^{79}$; y una trayectoria laboral con más interrupciones.

\footnotetext{
75 Ministerio de Trabajo y Economía Social, Informe del Mercado de Trabajo de las Mujeres 2020 (datos 2019). Madrid: MTES, 2020. Disponible en https://www.sepe.es/HomeSepe/que-es-el-sepe/comunicacion-institucional/publicaciones/publicaciones-oficiales/listado-pub-mercado-trabajo/informe-mercadotrabajo-estatal-mujeres.html

${ }^{76}$ BALLESTER PASTOR, M.A., La discriminación retributiva por... op. cit.p. 20.

${ }_{77}$ De Haro Fernández, A. M., "Heroínas y mercenarias. La violencia económica de género a través de su reflejo en la literatura inglesa", Violencia desenfocada IV. Dinero. Cuarta edición de las Jornadas de estudio, reflexión y opinión sobre violencia. Sevilla, 2008. p. 174. Actualmente también se hace referencia a "suelo pegajoso" o "techo de cemento", CEBRIÁN I.; Moreno, G.E, "Desigualdades de género en el mercado laboral”, Panorama Social, núm. 27, 2018. p. 47.

${ }^{78}$ MinisTERIO DE CiENCIA, InNOVACIÓN Y UniversidAdEs. Inserción laboral de los egresados universitarios, curso 20132014 (análisis hasta 2018). Madrid: Ministerio de Ciencia, Innovación y Universidades, 2019. Disponible en https:// www.ciencia.gob.es/stfls/MICINN/Universidades/Ficheros/Estadisticas/INFORME_INSERCION_2013_14.pdf

${ }^{79}$ SÁEz LARA, C., "OIT 100 años: la participación de las mujeres en el mercado de trabajo", en AA.VV., El futuro del trabajo: cien años de la OIT : ponencias. Madrid: Ministerio de Trabajo, 2019. p. 135.
} 


\subsection{Minusvaloración del trabajo femenino}

Este segundo factor hace referencia a la diversidad de la clase de trabajo, de sus exigencias formativas, profesionales y de cualificación. Ello se refleja, en la práctica, en la ordenación jerarquizada de los puestos de trabajo, niveles, profesiones o especialidades que se instrumenta a través de los sistemas de clasificación profesional; y en la determinación de la estructura y composición de los salarios ${ }^{80}$.

De esta forma, en primer lugar, son los sistemas de clasificación profesional los que ocultan una importante brecha salarial, pues, a pesar de que ya no se aprecian categorías profesionales en femenino o en masculino, se observa que la mayor parte de las estructuras profesionales de los convenios colectivos optan por el "sistema global", sistema muy genérico e impreciso a la hora de definir el contenido de los diferentes grupos o niveles profesionales. Ello se traduce en un mayor margen de discrecionalidad para la empresa, y en una mayor dificultad para detectar arbitrariedades o desigualdades ${ }^{81}$. No obstante, además, junto a esa imprecisión, en la definición de las estructuras profesionales de los convenios colectivos, y aún a pesar de la tendencia a utilizar términos neutros, aún subsisten sesgos sexistas en los descriptores de los grupos, especialidades y funciones ${ }^{82}$.

La incorrecta valoración de los puestos de trabajo está íntimamente ligado con las percepciones de los sujetos en torno a la valoración del trabajo realizado por mujeres y hombres debido a la desigual asignación de valor del trabajo, interiorizada en el aprendizaje social. Ello halla su razón, entre otras, en estereotipos que tradicionalmente han infravalorado los trabajos desarrollados por mujeres ${ }^{83}$.

A ello, cabe adicionar la "opacidad retributiva", con unas estructuras salariales opacas y ausentes de información disponible sobre los niveles salariales de las personas trabajadoras. Esta opacidad retributiva se manifiesta tanto en la configuración del convenio por la empresa de las retribuciones variables de diferente naturaleza cuya aplicación concreta está condicionada a la concurrencia de factores imprecisos o arbitrarios carentes de objetividad; así como cuando no es posible acceder a la retribución abonada al resto de personas trabajadoras de la empresa ${ }^{84}$. En el primer caso, concurre opacidad en la configuración de los complementos cuando quedan vinculados a que se consiga un objetivo que no se encuentra definido (como complementos vinculados a la calidad del trabajo) o

\footnotetext{
${ }^{80}$ MARTínez MoReno, C., Brecha salarial de género y discriminación retributiva: causas y vías para combatirlas. Albacete: Bomarzo, 2019. p. 41.

${ }^{81}$ ALEMÁn PÉREZ, F., “Consideraciones teóricas sobre los elementos de clasificación y los sistemas de encuadramiento: hacia una comprensión político-espiritual de los sesgos discriminatorios por razón de sexo y género", en GARRIGUES GimÉnEz, A., (Dir.) Clasificación profesional y discriminación por razón de sexo en la negociación colectiva. Un análisis multi e intersectorial. Madrid: Reus, 2017. p. 59.

${ }^{82}$ Rivas VAlLEjo, R., "Servicios (Y2): actividades administrativas y servicios auxiliares. Actividades financieras, seguros e inmobiliarias. Educación. Actividades sanitarias”, en GARRIGUEs GiménEz, A., (Dir.) Clasificación profesional y discriminación por razón de sexo en la negociación colectiva. Un análisis multi e intersectorial. Madrid: Reus, 2017. p. 123.

${ }^{83}$ BALlester PASTOR, M.A., La discriminación retributiva por... p. 24. Así, por ejemplo, en la STSJ País Vasco, de 30 de abril de 2019, rec. núm. 638/2019, que determina la existencia de una discriminación indirecta por razón de sexo cuando coexisten dos categorías distintas en el mismo nivel salarial, pero con diferentes salarios, por lo que, ante una práctica aparentemente neutra, se produce una desigualdad para una de dichas categorías, integrada mayoritariamente por mujeres.

${ }^{84}$ BALlester Pastor, M.A., La discriminación retributiva por... p. 25.
} 
cuando se establecen unos complementos que no tienen causa alguna o es ficticia. En segundo lugar, el conocimiento de la retribución abonada en la empresa al resto de personas trabajadoras resulta elemento esencial para poder detectar la existencia de discriminación retributiva. En España, hasta ahora existía una total opacidad. Con la nueva regulación, se aprueba la obligatoriedad de que conste un registro salarial, y además, de acceso por parte de la representación legal de las personas trabajadoras.

Asimismo, debe hacerse referencia a la necesidad de aplicarse la guía de la OIT del "Método de puntos por factor"85, que consiste en la asignación de puntuaciones a cada puesto de acuerdo con cuatro factores, cuales son, las cualificaciones, los esfuerzos mental, emocional y físico, las responsabilidades y las condiciones de trabajo. En relación con el primer elemento, esto es, las cualificaciones, se valora la formación, así como también la experiencia, elemento este último que resulta, en principio, lógico y proporcionado, pero que en la práctica, puede comportar una desventaja para las mujeres, pues son las que dedican parte de su tiempo y su vida a labores de cuidado a hijos o familiares ${ }^{86}$.

Por lo que se refiere al esfuerzo, se comprueba que sigue primando la fuerza física, a pesar de que respecto del mismo existe abundante doctrina constitucional, ya comentada anteriormente $^{87}$, que aclara los condicionantes que han de existir a la hora de valorar el esfuerzo para que éste no constituya discriminación por razón de sexo. El TC considera que cuando se tiene en cuenta el factor esfuerzo como criterio único de valoración es "sospechoso" por tratarse de una cualidad predominantemente masculina, aunque ello no significa que no pueda valorarse cuando sea esencial o determinante de la aptitud requerida, y siempre que se combinen con otros criterios neutros. Si se analiza la negociación colectiva se puede observar como, en general, prestan poca atención a otro tipo de dificultades o sacrificios como la carga mental o emocional propia de la actividad que se desarrolle, siendo el elemento a valorar el esfuerzo físico ${ }^{88}$.

En relación con el tercer elemento del método de la OIT, esto es, la responsabilidad, no cabe duda que es uno de los que más predomina en las descripciones de los puestos de trabajo mejor posicionados. No obstante, la responsabilidad no suele estar detallada con un contenido pormenorizado, sino que se referencia en los niveles más elevados de la estructura, en puestos de dirección y ejecutivos. De hecho, el art. 22.3 ET, en la modificación operada por el RDL 6/2019, establece que la definición de los grupos profesionales debe basarse en "criterios y sistemas que, basados en un análisis correlacional entre sesgos de género, puestos de trabajo, criterios de encuadramiento y retribuciones, tengan como objeto garantizar la ausencia de discriminación, tanto directa como indirecta, entre mujeres

\footnotetext{
${ }^{85}$ Disponible en https://www.ilo.org/wcmsp5/groups/public/@ed_norm/@declaration/documents/publication/ wcms_101326.pdf

${ }^{86}$ Martínez Moreno, C., Brecha salarial de género... op. cit. p. 45.

${ }^{87}$ Entre otras, SSTC 145/1991, de 1 de julio; 58/1994, de 28 de febrero; 147/1995, de 16 de octubre; 250/2000, de 30 de octubre; 198/1996, de 3 de diciembre; 286/1994, de 28 de noviembre.

${ }^{88}$ De igual modo lo considera la doctrina judicial, entre ellas, SSTSJ Canarias, de 25 de febrero de 2014, rec. núm. $1304 / 2013$, que señala que el esfuerzo físico puede justificar la diferencia "si se acreditase de forma indubitada que el esfuerzo físico constituye un elemento determinante absoluto de la aptitud para el desarrollo de la tarea, o bien, que se trate de un elemento esencial en esta, siendo preciso, aun en estos casos, que se combine con otros rasgos tipificadores neutros desde el punto de vista que interesa considerar".
} 
y hombres. Estos criterios y sistemas, en todo caso, cumplirán con lo previsto en el artículo 28.1". Ello es una muestra más de la existencia de una clara correspondencia entre la segregación ocupacional, la falta de claridad y neutralidad de los sistemas de clasificación profesional, la valoración de los puestos y la discriminación salarial por razón de sexo.

Por otro lado, pero íntimamente ligado al sistema de clasificación profesional, se observan patrones muy similares en la estructura salarial, pues se parte de la concepción de que el trabajo femenino exige menos cualificación, esfuerzo y responsabilidad, por lo que aporta menos valor integral a la actividad de la empresa y, por consiguiente, no se encuentra en el mismo nivel que el de las personas trabajadoras masculinas. Así, en el caso ya comentado de Galletas Fontaneda ${ }^{89}$, nuestro TC, declara que no puede estar justificado que unos trabajos valgan más que otros en virtud de su mayor nivel de exigencia y su mayor "significación cualitativa en el proceso productivo", sino que se ve perpetuado ese círculo vicioso por el que se considera que las mujeres realizan tareas menos valoradas.

De esta forma, si se toman en cuenta los diferentes complementos salariales puede observarse como, en primer lugar, en relación con los complementos personales, la antigüedad es uno de los pluses que, a pesar de su intento por ser eliminado, comporta un factor discriminatorio en la medida en que son las mujeres trabajadoras las que sufren más interrupciones y discontinuidades en su carrera profesional por aspectos ligados a la maternidad y cuidado de hijos, además de que son las que más sufren contratos temporales y de rotación, en comparación con los trabajadores varones.

En segundo lugar, por lo que se refiere a los complementos ligados a las condiciones y circunstancias del puesto de trabajo, existe una clara brecha salarial cuando se observa que la mayor parte de los pluses se concentran en actividades industriales o características propias de la persona trabajadora varón, o que presuponen tareas masculinizadas, a diferencia de aquellos trabajos donde hay mayor presencia femenina que se suelen considerar más sencillos y, por tanto, con menos pluses vinculados. Claro ejemplo lo constituyen los complementos salariales de peligrosidad, penosidad, toxicidad, insalubridad, nocturnidad o turnicidad, pluses que generalmente se establecen en puestos de trabajo desempeñados por personas trabajadoras masculinas ${ }^{90}$. Asimismo, es de destacar como en aquellas actividades propias del sector servicios -donde están más presentes las mujeres-, los pluses más frecuentes son los relacionados con la mayor dedicación, puntualidad, asiduidad, disponibilidad o prolongación de la jornada, pluses todos ellos incompatibles con la pretensión de alcanzar la conciliación de la vida familiar y laboral. Estos pluses, como se ha indicado, aunque, en principio, no son discriminatorios, por su carácter neutro, sin embargo, en la práctica, comportan una diferenciación discriminatoria. De igual forma, los pluses relacionados con el rendimiento, resultados, jefatura o responsabilidad también conllevan efectos discriminatorios, de tal forma que sólo en la medida en que los mecanismos de atribución de funciones o asignación del personal a los puestos de mayor

\footnotetext{
${ }^{89}$ STC 286/1994, de 28 de noviembre.

${ }^{90}$ STS Canarias, de 2 de julio de 2019, rec. núm. 369/2019, en relación con un hotel que es sancionado por no realizar la valoración ergonómica de los puestos de trabajo de las empleadas del departamento de pisos.
} 
nivel, y los sistemas de medición objetiva del rendimiento se encuentren reglados y objetivados y giren en torno a la equidad, serán logros reales ${ }^{91}$.

En muchos casos, además, se observan diferencias que tienen lugar en la plasmación de que determinados complementos tienen una cuantía sensiblemente inferior cuando se asignan a puestos de trabajo ocupados mayoritariamente por mujeres, en comparación cuando el mismo complemento va ligado a un departamento o puesto de trabajo donde predominan trabajadores masculinos ${ }^{92}$.

\subsection{División sexual del trabajo}

Este tercer factor de discriminación salarial entre mujeres y hombres es una variable "transversal" en la medida en que tiene repercusión en todos los ámbitos de la vida, así como en educación, formación y ámbito laboral.

No cabe duda que la situación familiar, el nivel educativo y la ocupación de las padres, la renta familiar, el sopeso de los pros y contras del abandono de los estudios para incorporarse al sistema productivo; la organización del hogar; la economía doméstica y la división sexual del trabajo son factores que afectan decisivamente en la elección de los estudios, la continuidad de los mismos, el perfil formativo, la inversión en cualificación y la búsqueda de empleo. Y ello no afecta de igual forma a mujeres que a hombres ${ }^{93}$.

Además, por otro lado, en la fase de tránsito de la etapa educativa a la de inserción y permanencia en el mercado de trabajo, queda constatado que los hombres mantienen una evolución más lineal, alternando etapas de formación para el empleo, mientras que en el caso de las mujeres, a pesar de que tratan de formarse, tienen menores oportunidades de ocupación y promoción, así como están expuestas a una mayor discontinuidad en el empleo ${ }^{94}$. Adicionalmente, debe hacerse referencia al condicionante de la maternidad, su condición biológica de madres potenciales o reales, la consecuente división sexual del trabajo, la diferente carga de trabajo doméstica y la desigual distribución en el uso del tiempo. Es una realidad que las mujeres siguen trabajando más que los varones en labores

${ }^{91}$ STS de 18 de julio de 2011, rec. núm. 133/2010, que, partiendo de los datos de personas trabajadoras ocupadas, ascensos productivos, y número de puestos de ascenso ocupados por hombres y mujeres, considera que existía una desproporción entre el número de hombres ascendidos respecto de la composición de las plantillas. De similar forma, STS de 14 de mayo de 2014, rec. núm. 2328/2013, sobre una empresa hotelera que abonaba a sus empleados de los departamentos de cocina, bares y pisos, un "plus voluntario absorbible", siendo diferente para el departamento de pisos (ocupado por mujeres en su totalidad).

${ }_{92}$ STS Andalucía, de 14 de febrero de 2018, rec. núm. 2089/2017. Así también STSJ Canarias, de 2 de noviembre de 2017, rec. núm. 461/2017, sobre el plus de productividad, cuantificado de forma diferente según sea para el departamento de pisos (ocupado en un $92 \%$ por mujeres) que para el resto de trabajadores (ocupado en un $85 \%$ por hombres).

${ }^{93}$ Martínez Moreno, C., Brecha salarial de género... op. cit. p. 63.

${ }^{94}$ STC $2 / 2017$, de 16 de enero, que constata cómo la ausencia por maternidad supuso un inconveniente para que la trabajadora pudiera acceder a un empleo con una jornada superior tal y como preveía el convenio de aplicación. Se trataba de una limpiadora adscrita a un centro de salud con un contrato a tiempo parcial de 20 horas semanales, y durante el tiempo que la actora estuvo de baja por maternidad, la empresa contrató a una trabajadora con un contrato de 30 horas semanales. En el momento de reingresar de la baja, la afectada solicitó ejercitar el derecho a ampliar la jornada prevista en el convenio que establece esta medida con preferencia a la realización de nuevas contrataciones, y la empresa se deniega. 
domésticas y de cuidado, con independencia de cualquier otra variable como la situación familiar. Muestra de ello es que las mujeres solteras ganan más de media que las casadas, al revés de que ocurre en el caso de los hombres.

En este sentido, no cabe duda que una de las condiciones de trabajo que mayor impacto negativo tiene sobre las mujeres trabajadoras es el trabajo a tiempo parcial, especialmente en materia de protección social de las mismas. Al respecto, la doctrina judicial comunitaria ${ }^{95}$ ha señalado, en materia de pensión de jubilación y prestación de desempleo, que la normativa española de acceso a las prestaciones de la Seguridad Social de las personas trabajadoras a tiempo parcial conlleva una discriminación indirecta. Como consecuencia, nuestro $\mathrm{TC}^{96}$ ha declarado que el coeficiente de proporcionalidad que se aplica en el cálculo de la pensión de jubilación de las personas trabajadoras a tiempo parcial es nulo por discriminatorio para la mujer, ya que conlleva que exista una desigualdad entre las personas trabajadoras a tiempo parcial y a tiempo completo.

Además del contrato a tiempo parcial, se han evidenciado situaciones donde la maternidad ha conllevado efectos negativos sobre las retribuciones, especialmente, las variables vinculadas a sistemas de incentivos u objetivos. Así el $\mathrm{TS}^{97}$ se ha pronunciado en relación con un sistema salarial de una empresa en el que se descontaban de los días exigidos para el devengo de un incentivo, los días de duración del permiso por maternidad correspondiente al período de descanso obligatorio, esto es, las seis semanas posteriores al parto, considerando nuestro alto tribunal que "la protección de la condición biológica y de la salud de la mujer trabajadora ha de ser compatible con la conservación de sus derechos profesionales, de suerte que la minusvaloración o el perjuicio causado por el embarazo o la sucesiva maternidad constituye un supuesto de discriminación directa por sexo". De igual forma lo ha estimado ${ }^{98}$ también en un sistema de retribución variable establecido en la empresa consistente en dos incentivos, ninguno de los cuales se devenga cuando no hay actividad laboral como es durante los períodos de baja por maternidad o por riesgo durante el embarazo, lo cual conlleva que la persona trabajadora no perciba esos complementos hasta que haya completado el correspondiente período de devengo. Así sucedió también en el caso del "complemento de atención continuada" que se le deja de abonar a una médico residente que durante su embarazo, y como medida de adaptación del puesto de trabajo ex art. 26 LPRL, dejó de realizar guardias, ante lo cual, la dirección del hospital, con el fin de reequilibrar la situación de la actora respecto de sus compañeros, decide prorrogar la duración de su contrato por el tiempo necesario para que pudiera "recuperar"

${ }^{95}$ STJUE de 8 de mayo de 2019, C-161/2018, asunto Villar Láiz. También STJUE de 22 de noviembre de 2012, C-385/2011, asunto Elbal Moreno, que aplica la prueba estadística considerando que los datos aportados por el tribunal de procedencia eran irrefutables, pues entre el 70 y el $80 \%$ de las personas trabajadoras a tiempo parcial tanto vertical como horizontal, mientras que el efecto perjudicial de la medida nacional es común para todos los trabajadores a tiempo parcial vertical, la mayor parte mujeres. El TJUE considera que la proyección del principio de proporcionalidad sobre el cálculo de la pensión incurre en una doble penalización. Primero, en la determinación de la base reguladora, que es más baja al serlo el salario; y, segundo, en la aplicación del coeficiente de parcialidad, pese a que a los días cotizados se les aplica un coeficiente corrector del 1,5 que incrementa la ratio de cotización. También la STJUE de 20 de octubre de 2011, C-123/2010, asunto Brachner.

${ }^{96}$ STC 91/2019, de 3 de julio.

${ }^{97}$ STS de 23 de noviembre de 2011, rec. núm. 3627/2010.

${ }^{98}$ STS de 10 de enero de 2017, rec. núm. 283/2015. 
el mismo número de guardias. Nuestro TS considera que ello "constituye discriminación directa por razón de sexo" ${ }^{\prime 99}$. Sin embargo, en el caso de un plus de fin de semana que se abonaba en proporción a la reducción de jornada por cuidado de menores no se considera discriminatoria por afectar la reducción más al personal masculino que al femenino, por ser el personal masculino el que disfruta mayoritariamente de la reducción de jornada ${ }^{100}$.

\section{Medidas para la igualdad retributiva}

Como se ha indicado, el RD 902/2020 implementa unos instrumentos en las empresas para garantizar el principio de transparencia retributiva y conseguir la igualdad retributiva, concretamente, el registro retributivo, la auditoría salarial y el sistema de valoración de puestos de trabajo.

La transparencia retributiva es el eje fundamental para garantizar una igualdad retributiva real y efectiva, pues el problema de la discriminación se halla en la identificación y la prueba, para lo cual, la transparencia en el acceso a la información es la clave de su éxito. Debe garantizarse una información periódica a personas trabajadoras y sus órganos de representación, tal y como así ya lo establecía la Recomendación de la Comisión Europea de 2014.

En primer lugar, el registro retributivo (art. 5 RD 902/2020) es obligatorio para todas las empresas, con independencia del número de personas trabajadores, lo que supone una mejora en relación con la Recomendación de la Comisión de 7 de marzo de 2014, que lo fijaba a las de 50 o más personas trabajadoras.

Este registro además, debe cumplir los siguientes parámetros. En primer lugar, debe incluir toda la plantilla, incluido personal directivo y altos cargos; y debe contener información fiel y actualizada. En segundo lugar, debe contemplar el año natural. En tercer lugar, debe documentarse en el formato establecido en las páginas web oficiales del Ministerio de Trabajo y Economía Social y del Ministerio de Igualdad. En cuarto lugar, debe incluir datos promediados y desglosados, concretamente, valores medios del salario base, complementos salariales y percepciones extrasalariales desagregados por sexos, media aritmética y mediana de lo realmente percibido en función del sistema de clasificación (grupo, categoría, nivel y puesto), y en caso de empresas con obligación de auditoría re-

${ }^{99}$ STS de 24 de enero de 2017, rec. núm. 1902/2015. En sentido similar, STJUE de 1 de julio de 2010, C-471/2008, asunto Parviainen contra Finnair Oyj, donde admite que los complementos de una azafata de vuelo que durante el embarazo pasa a desempeñar un puesto en tierra vinculados con el hecho de volar no se perciban durante ese período de tiempo. De modo similar, STSJ Cataluña, de 6 de abril de 2018, rec. núm. 7434/2017, que enjuicia la forma de cálculo de las retribuciones variables durante el período en el que no hay prestación de servicios por suspensión del contrato por maternidad o riesgo durante el embarazo, o en casos de reducción de jornada por guarda de un menor.

${ }^{100}$ STSJ Castilla y León, de 10 de octubre de 2019, rec. núm. 1490/2019, que declara que durante la mayor parte del tiempo desde la firma del acuerdo la empresa abonó el plus de fin de semana en proporción a la jornada efectivamente realizada. Considera que no existe discriminación porque "la mayor parte de beneficiarios de la reducción de jornada para cuidado de menor o familiar en el tiempo que nos ocupa (marzo 2018) no eran mujeres sino hombres, con lo que difícilmente puede apreciarse en la actuación empresarial una maniobra discriminatoria, lesiva del derecho de igualdad por razón de sexo en contra del colectivo femenino, al ser mayoritariamente masculino el afectado dentro de la empresa por la decisión empresarial". 
tributiva (las que ocupen a más de 50 personas trabajadoras) debe incluir también las medias aritméticas y medianas de las agrupaciones de los trabajos de igual valor en la empresa, aunque pertenezcan a diferentes apartados de la clasificación profesional, desglosados por sexo y desagregados e incluir la justificación cuando la media aritmética o la mediana de las retribuciones totales en la empresa de las personas trabajadoras de un sexo sea superior a las del otro en, al menos, un $25 \%$. En quinto lugar, para su elaboración o modificación debe procederse a la consulta a la representación legal de las personas trabajadoras con una antelación de, al menos, diez días. En sexto lugar, en cuanto al acceso a su información, la representación legal de las personas trabajadoras tiene acceso al contenido íntegro del registro, y en el supuesto de que no exista representación legal, las personas trabajadoras podrán acceder únicamente a las diferencias porcentuales en las retribuciones promediadas de hombres y mujeres, desagregadas en atención a la naturaleza de la retribución y el sistema de clasificación profesional.

En segundo lugar, en cuanto a la auditoria retributiva, ésta tiene por objeto verificar el cumplimiento del principio de igualdad, evitar y corregir diferencias y prevenir obstáculos y dificultades, asegurando la transparencia. Esta obligación mejora también la Recomendación de la Comisión UE que lo limitaba a empresas con más de 250 personas trabajadoras. En nuestro caso, se vincula a la aprobación del plan de igualdad que, como es sabido, debe implantarse para empresas de más de 50 personas trabajadoras. La vigencia de la auditoría es la del plan de igualdad del que forma parte.

La auditoría (art. 8 RD 902/2020) supone la necesidad de realizar un diagnóstico de la situación retributiva de la empresa, esto es, evaluar los puestos de trabajo sobre cada una de las tareas y funciones de cada puesto, y detectar otros factores desencadenantes de la diferencia retributiva, deficiencias o desigualdades, o dificultades para la promoción económica de las personas trabajadoras como actuaciones empresariales discrecionales en materia de movilidad o exigencias de disponibilidad no justificadas. Esa evaluación supone además un examen global de todos los factores que concurren en un puesto de trabajo, teniendo en cuenta su incidencia y permitiendo la asignación de un valor numérico objetivo; y, además, la valoración debe referirse a cada una de las tareas y funciones y ofrecer resultados con confianza en función y adecuado al sector de actividad al tipo de organización en la empresa y otras características con independencia del tipo de contrato. Pone de manifiesto, además, la relevancia de otros factores desencadenantes de la diferencia retributiva, así como las posibles deficiencias o desigualdades que pudieran apreciarse en el diseño de las medidas de conciliación y corresponsabilidad en la empresa, o las dificultades que las personas trabajadoras pudieran encontrar en su promoción profesional o económica derivadas de otros factores como las actuaciones empresariales discrecionales en materia de movilidad o las exigencias de disponibilidad no justificadas.

Asimismo, debe establecer un plan de actuación de corrección de desigualdades que incluya objetivos, actuaciones, cronograma, indicación de personas responsables y sistema de seguimiento. El plan de actuación debe contener un sistema de seguimiento y de implementación de mejoras a partir de los resultados obtenidos. 
Además, y adicionalmente a dichos instrumentos, para garantizar la ausencia de discriminación en la definición de grupos profesionales, las partes negociadoras de los convenios deben asegurarse de que los factores y condiciones en cada uno de los grupos y niveles profesionales respetan los criterios de adecuación, totalidad y objetividad, así como el principio de igual retribución.

Por último, como elemento fundamental, a mi parecer, es el sistema de valoración de los puestos de trabajo (art. 9 RD 902/2020), según el cual, con el objetivo de comprobar que la definición de los grupos profesionales se ajusta a criterios y sistemas que garantizan la ausencia de discriminación directa e indirecta entre mujeres y hombres y la correcta aplicación del principio de igualdad de retribución por trabajos de igual valor, las mesas negociadoras de los convenios colectivos deberán asegurarse de que los factores y condiciones concurrentes en cada uno de los grupos y niveles profesionales respetan los criterios de adecuación, totalidad y objetividad, y el principio de igual retribución para puestos de igual valor.

\section{Conclusión}

Con la modificación normativa y su desarrollo reglamentario que establece la obligación de garantizar el principio de transparencia retributiva mediante el registro salarial, la auditoría salarial y la información periódica, se implementan varias de las medidas que la doctrina laboral ${ }^{101}$ en su momento ya propuso.

De esta forma, para poder alcanzar una igualdad retributiva se requiere como base, y con el fin de garantizar esa transparencia retributiva, una correcta valoración de los puestos de trabajo, pues de esta forma, el registro salarial y la auditoría salarial aportarán resultados positivos. El ordenamiento laboral debe contener también un concepto de trabajo de igual valor más completo, como el que se ha redactado con el RDL 6/2019 donde se refuerza la idea de una valoración objetiva de los puestos de trabajo. Además, es fundamental garantizar un sistema efectivo de información a las personas trabajadoras y a sus órganos de representación sobre la retribución promediada y desglosada en la empresa, esto es, la transparencia de los datos salariales es necesaria para poder identificar si existe discriminación retributiva. Asimismo, tal y como ya apuntó también la doctrina ${ }^{102}$, es fundamental establecer auditorías salariales obligatorias, auditorías que deben estar reguladas en los planes de igualdad.

Como medidas complementarias, la doctrina ${ }^{103}$ propuso también la creación de órganos administrativos específicos para la eliminación de la discriminación retributiva, como podría ser crear una unidad especialidad en materia de igualdad de trato en todas las Inspecciones Provinciales de Trabajo y Seguridad Social así como la creación de una Dirección General para la igualdad retributiva dependiente de la secretaria de Estado de

\footnotetext{
${ }^{101}$ BALLESTER PASTOR, M.A., La discriminación retributiva por... p. 81 y ss.

${ }^{102}$ BALLESTER PASTOR, M.A., La discriminación retributiva por... p. 83 y ss.

${ }^{103}$ BALlESTER PASTOR, M.A., La discriminación retributiva por... p. 83 y ss.
} 
servicios sociales y de una Comisión Interministerial. Debería desarrollarse un marco sancionador efectivo y disuasorio, y todas las medidas que se acometan deben tener su correspondiente reflejo en la LISOS. Así como también procederse a la remoción de obstáculos para la reclamación judicial por discriminación retributiva, y la existencia de técnicos expertos en igualdad de género en negociación y representación en las Administraciones Públicas, especialmente en materia de correcta valoración de los puestos de trabajo.

Estas medidas son las que ha llevado a cabo el RD 902/2020, todas ellas propuestas ya en su día por la doctrina y que han tenido su plasmación en el citado reglamento. De esta forma, se espera que progresivamente desaparezca la brecha salarial y se alcance la igualdad retributiva, igualdad que se basa en el principio de igualdad retribución por trabajo de igual valor, con independencia del sexo, para lo cual, el principio de transparencia retributiva constituye el elemento de medición y contrastación. Este principio de transparencia se aplica a través del registro salarial, la auditoría salarial y el sistema de valoración de puestos de trabajo, así como el derecho de información de las personas trabajadoras.

\section{Bibliografía}

AA.VV., Evaluación de tareas. Ginebra: OIT, 1986.

ALEMÁN PÉREZ, F., "Consideraciones teóricas sobre los elementos de clasificación y los sistemas de encuadramiento: hacia una comprensión político-espiritual de los sesgos discriminatorios por razón de sexo y género", en GARRIGUEs GiméNEZ, A., (Dir.) Clasificación profesional y discriminación por razón de sexo en la negociación colectiva. Un análisis multi e intersectorial. Madrid: Reus, 2017.

BALLESTER PASTOR, M.A., La discriminación retributiva por razón de sexo. Brecha salarial y desigualdades de género en el mercado de trabajo. Albacete: Bomarzo, 2018.

BASE DE DATOS ESES, Informe mundial sobre salarios 2018/2019, OIT, 2019.

CEBRIÁN I.; MORENO, G.E, "Desigualdades de género en el mercado laboral”, Panorama Social, núm. 27, 2018.

COMISIÓN EUROPEA, La brecha salarial entre hombres y mujeres en la Unión Europea, 2014. Disponible en https://ec.europa.eu/info/policies/justice-and-fundamentalrights/gender-equality

DE HARO FERNÁNDEZ, A. M., "Heroínas y mercenarias. La violencia económica de género a través de su reflejo en la literatura inglesa", Violencia desenfocada IV. Dinero. Cuarta edición de las Jornadas de estudio, reflexión y opinión sobre violencia. Sevilla, 2008.

LOUSADA AROCHENA, J.F., El derecho fundamental a la igualdad efectiva de mujeres y hombres. Fundamentos del derecho a la igualdad de género y, en especial, su aplicación en el Derecho del Trabajo y de la Seguridad Social. Valencia: Tirant lo Blanch, 2014 (versión on line)

MARTÍNEZ MORENO, C., Brecha salarial de género y discriminación retributiva: causas y vías para combatirlas. Albacete: Bomarzo, 2019. 
MINISTERIO DE CIENCIA, INNOVACIÓN Y UNIVERSIDADES. Inserción laboral de los egresados universitarios, curso 2013-2014 (análisis hasta 2018). Madrid: Ministerio de Ciencia, Innovación y Universidades, 2019. Disponible en https://www.ciencia.gob.es/stfls/MICINN/Universidades/Ficheros/Estadisticas/informe_insercion_2013_14.pdf

MINISTERIO DE SANIDAD, SERVICIOS SOCIALES E IGUALDAD. "Brecha salarial y científica de género", en Boletín Igualdad Empresa. Madrid: Ministerio de Sanidad, Servicios Sociales e Igualdad, 2018. Disponible en http://www.igualdadenlaempresa.es/novedades/boletin/docs/BIE_44_Brecha_salarial_y_cientifica_de_genero.pdf

MINISTERIO DE TRABAJO Y ECONOMÍA SOCIAL, Informe del Mercado de Trabajo de las Mujeres 2020 (datos 2019). Madrid: MTES, 2020. Disponible en https://www.sepe.es/ HomeSepe/que-es-el-sepe/comunicacion-institucional/publicaciones/publicacionesoficiales/listado-pub-mercado-trabajo/informe-mercadotrabajo-estatal-mujeres.html

QUINTANILLA NAVARRO, B., Discriminación retributiva. Diferencias salariales por razón de sexo. Madrid: Marcial Pons, 1996.

REY MARTÍNEZ, F., El derecho fundamental a no ser discriminado por razón de sexo. Madrid. McGraw-Hill, 1995.

RIVAS VALLEJO, R., "Servicios (Y2): actividades administrativas y servicios auxiliares. Actividades financieras, seguros e inmobiliarias. Educación. Actividades sanitarias”, en GARRIGUES GimÉNEZ, A., (Dir.) Clasificación profesional y discriminación por razón de sexo en la negociación colectiva. Un análisis multi e intersectorial. Madrid: Reus, 2017.

RODRÍGUEZ ESCANCIANO, S., "Sobre el valor del trabajo y la paridad salarial por razón de género ante una controvertida sentencia del Tribunal de Justicia de la Comunidad Europea (Comentario a la STJCE C-320/2000, de 17 de septiembre de 2002, asunto Lawrence)", $R L$, núm. 12, 2005 (versión on line)

RODRÍGUEZ-PIÑERO y BRAVO-FERRER, M., "Feminización de tareas y masculinización de valoraciones", $R L$, núm. 3, 2001.

SÁEZ LARA, C., "OIT 100 años: la participación de las mujeres en el mercado de trabajo", en AA.VV., El futuro del trabajo: cien años de la OIT : ponencias. Madrid: Ministerio de Trabajo, 2019.

SÁEZ LARA, C., Mujeres y mercado de trabajo. Madrid: CES, 1994.

SERRA CRISTÓBAL, R., "La discriminación indirecta por razón de sexo", en RIDAURA MARTÍNEZ, J.; AZNAR GÓMEZ, M., (Coords.) Discriminación versus diferenciación (Especial referencia a la problemática de la mujer). Valencia: Tirant lo Blanch, 2004. 